\title{
Firm Corruption in the Presence of an Auditor
}

\author{
MICHAEL DIETRICH \\ University of Sheffield* \\ JOLIAN MCHARDY \\ University of Sheffield
}

\begin{abstract}
ABHIJIT SHARMA
Bradford University School of Management,

We develop a theoretical framework exploring firm corruption accounting for interactions with an auditor who provides auditing and other services. A multiplicity of equilibria can exist including stable corruption and auditor controlled corruption. Whilst fining the auditor cannot eliminate all corruption, fining the firm can, but marginal increases in this fine can also have perverse effects. Investing in corruption detection may be effective in deterring auditor corruption but ineffective in deterring firm corruption. Policy effectiveness is highly dependent upon several factors which may be hard to observe in practice making general rules about policy interventions to address corruption very difficult.
\end{abstract}

Keywords: firm corruption; auditor corruption

JEL Classifications: D73; K42; L21

\section{Introduction}

This paper focuses on the role of firms and the incentives they face within the context of complex interplay between institutions, government and firms in determining opportunities for engaging in rent-seeking behaviour and corrupt activity. Previous research has largely focused on corruption where government or other state actors play the central role, typically in a procurement or government tendering context, where if firms are involved their role is typically reactive (see, for example Rose-Ackerman, 1999, 2007; Lessmann and Markwardt, 2010; Waller et al, 2012; Wadho, 2016; Dufwenberg and Spagnolo, 2015). Corruption within

"Dietrich and McHardy: Department of Economics, University of Sheffield, m.dietrich@sheffield.ac.uk; J.Mchardy@shef.ac.uk; Sharma: Accounting Finance and Economics Group, Bradford University School of Management, A.Sharma12@bradford.ac.uk

(C) 2016 Michael Dietrich, Jolian McHardy and Abhijit Sharma. Licensed under the Creative Commons Attribution - Noncommercial 3.0 Licence (http://creativecommons.org/licenses/bync/3.0/. Available at http://rofea.org. 
extraction industries, including non-renewable resource sectors, is one possible exception (see, for example Arezki, 2011). Nonetheless, firm level corruption has been a significant problem. Between 1997 and 2002, nearly 10 per cent of US listed companies restated their earnings at least once due to accounting irregularities (cited in Aglietta and Reberioux, 2005). In addition, earnings restatements were effected in 414 cases involving US based firms in 2004 because of financial irregularities (cited in Coffee, 2005). The empirical work reported in Goel (2014) also suggests the importance of a firm level orientation. He finds, using US data for 1970-2009, that there is a significant positive link between corporate political action committees and corruption. These irregularities provide a background for Jensen's (2006, p.14) reference, while discussing the overvaluation of equity in the late 1990s and early 2000 s, to the prevalence of: “.. misleading data from managers, large numbers of naive investors, and breakdowns in the agency relationship within companies, in investment banks, and in Audit and law firms many of whom knowingly contributed to the misinformation that fed the overvaluation."

A similar view is presented by Stiglitz (2003, p.244), who, whilst discussing Enron suggests that: "It appears that its [Enron's] chief financial officer made the same discovery that so many other corporate executives made during the nineties: the same accounting tricks that could be used to distort information to boost stock market prices could be used to enrich themselves at the expense of other shareholders." Key issues emerge from the Jensen-Stiglitz opinions cited here. Firm corruption involves (a) a breakdown in agency relationships; (b) misleading activity not only by managers but also by audit firms (for example); and (c) 'accounting tricks' that were increasingly becoming standard. Given these, it is apparent that only some firms were corrupt, even though (following Stiglitz) the 'tricks' were becoming standard. The 414 cases of earnings restatements is a significant number but a small proportion of the total number of US firms. Hence many firms decided not to do what was apparently 'standard' practice. A preliminary conclusion might therefore suggest itself: a breakdown in agency relationships is a necessary but not sufficient condition for firm corruption. Sufficiency would appear to require (1) an agency breakdown in the relationship between firms and their owners; (2) a willingness on the part of firms to exploit this and engage in 'tricks'; and possibly also (3) collusion by supporting actors (e.g. auditing firms) in the 'tricks'.

While the basic idea in our framework is that firm corruption involves collusion between firms and auditors, a central problem exists in this relationship where auditors provide auditing and other consultancy services. The extent of these 'other' services depends on firm profitability i.e. the ability to buy them. In turn, firm and auditor profitabilities increase with corruption. This can provide an incentive for, not only firm corruption, but also auditor collusion in this corruption. The core problem analysed in this paper has, of course, been recognised by other authors. For example Posner (2006, p. 11) gives a characteristically pithy summary of 


\section{DIETRICH, MCHARDY, SHARMA Firm Corruption in the Presence of an Auditor}

the core idea for the current discussion: "Corporate executives, moreover, hire and pay the auditors who certify the correctness of the corporation's financial statements, dangle consulting contracts in front of auditors who also offer consulting services." Our work is also related in parts to Pagano and Immordino (2007) and Ravikumar and Zhang (2012) who consider a similar question involving optimal auditing. However, rather than optimal auditing per se, this work recognises the importance of viewing auditing in a strategic context consistent with these other contributions, and focuses on the circumstances under which corruption can be an equilibrium outcome.

In this paper a framework is developed that assumes agency breakdown has occurred and explores the possibility of firms exploiting this and possible collusion by auditing firms. The framework applies to corruption aimed at financial gain by both firm and auditor and when this leads to a stable (equilibrium) outcome. ${ }^{1}$ Ideas akin to the firm/agent collusion in the corruption process have been addressed elsewhere in the literature. Lambert-Mogiliansky and Sonin (2006) analyse corruption and collusion in procurement. They argue that a corrupt agent would be willing to 'sell' his decision in return for a bribe. They also argue that the risks of collusion and of corruption need to be addressed simultaneously and indicate the potential for an external agent (an auctioneer) in having a role in providing the conditions which allow the stability of corruption and extracting of rents. The idea that an external agent may facilitate corruption as a stable equilibrium is used in this paper, but the emphasis is shifted from the external agent being an auctioneer to being an auditor. Carrillo (2000) constructs a dynamic model of corruption within which agents are aware of their 'propensity for corruption' and their clients choose an optimal level of bribe to be offered. Such a framework provides an explanation for different implicit prices for illegal services (bribes or kick-backs) for similar countries (or organisations within similar countries), based on an analysis of reaction of clients. These ideas are carried forward into the current discussion: that there is a propensity for corruption and that the reactions of other agents (here auditors) are important for the equilibria that can be generated. In a context similar to this paper, Samuel (2009) employs a principal (or regulator), a supervisor (similar to our auditor) and firms, and considers a situation where the supervisor expends considerable effort to obtain information which, if revealed, would lead to the agent being fined with a given probability. Of course, the supervisor may collude with the agent and hide this adverse information in exchange for a

\footnotetext{
${ }^{1}$ To illustrate the limits to the current discussion reference can be made to the case of Olympus. It is widely reported in the press that senior management in this company attempted to use corrupt accounting practices to cover investment losses. But two characteristics of this case suggest that it cannot be analysed using the framework developed here. First, the senior managers involved apparently did not make any personal financial gain from the corrupt practices. Second, while auditor collusion existed the suggestion is that the practices involved were incompetence rather than profit based. The framework developed here cannot cover corruption of this type.
} 
bribe. It is shown that raising the supervisor's reward discourages such ex-post corruption, but it can lead to increased pre-emptive collusion and corrupt behaviour.

Whilst corruption can take various forms, the approach adopted here concentrates on corrupt practices within a private firm sector in the form of misuse of corporate assets, as discussed, for example, in Svensson (2005). In particular a game theoretic framework is developed that examines incentives for firms to be corrupt given market-based monitoring by an auditor and to examine whether, and in what circumstances, stable, equilibrium corruption is possible.

Mishra (2006) demonstrates that a high level of corruption or a low level of compliance can become an equilibrium outcome, in spite of anti-corruption efforts. However, unlike our study, Mishra's analysis is based on evolutionary dynamics and involves social norms. It is chiefly directed at hierarchical and government type bureaucracies, rather than market based firms. The possibility of multiple equilibria involving corruption arising in the firm/agent context is demonstrated by Çule and Fulton (2009), although here the 'agent' interacting with the firm is a tax inspector and collusion involves bribes aimed at reducing tax liability.

Our paper makes contributions as follows. We explore firm corruption within a private sector, corporate decision making context. This is a relatively ignored area within the literature which tends to focus on government and government procurement related corruption. The firm corruption model developed here shows that multiple equilibria can arise. These solutions can be interpreted as a theoretical equivalent of the multiple behaviours observed in practice. Key equilibria, in terms of the objectives of the discussion, are the possibility of stable corruption but also auditor controlled corruption. In terms of possible policy implications that follow from the framework developed here, the following contributions are important. First, we demonstrate that fining the auditor cannot eliminate all corruption; this is arguably an important and counter-intuitive finding. Secondly, we also show that fining the firm can eliminate corruption. But, marginal increases in the firm's fine can also have perverse policy effects. A clear finding is that investing in corruption detection can be effective in controlling auditor corruption but ineffective in deterring firm corruption. Finally, we conclude that policy effectiveness is highly dependent upon several factors which are hard to observe in practice. This makes it hard to formulate general rules about policy interventions for addressing corruption, and hence indicates the potential relevance of a case by case approach.

The structure of the paper is as follows. The next section develops key assumptions involved with a corruption game and develops the theoretical model. Section three specifies explicit payoffs. Section four explores possible policy options for the players and regulatory body and identifies the extent to which players and the regulator can influence the equilibria of the game. The final section of the paper highlights a number of key policy conclusions that follow from the framework developed here. 
DIETRICH, MCHARDY, SHARMA Firm Corruption in the Presence of an Auditor

\section{The corruption game}

This paper considers the scenario of a firm that has the option of pursuing a profitmaking corrupt prospect in the knowledge that such corrupt activity would be detected by its auditor. However, the firm also purchases consultancy services from the auditor. We consider whether there are conditions under which corruption may be an equilibrium and examine the effectiveness of various regulatory policy interventions in dealing with corruption. We now set out the key modelling assumptions which underlie the framework of the corruption game.

In addition to Nature $(N)$, the game has two players: a Monopolist $(M)$ and an Auditor $(A)$. The players are risk neutral and expected profit maximisers. Each player's action set has two elements: Corrupt $(C)$ and Honest $(H)$. The players choose their actions sequentially over two periods: the Monopolist is assumed to be the leader and the Auditor the follower. Hence, with subscripts denoting the period $\{1,2\}$, we have: Period 1: $M$ chooses $\left\{C_{1}, H_{1}\right\}$; Period 2: A chooses $\left[\ldots,\left\{C_{2}, H_{2}\right\}\right]$. The game is one of complete and symmetric information allowing us to solve the game by backward induction. Consequently, when the Auditor selects its action, $\left\{C_{1}, H_{1}\right\}$ is known.

We now begin to set out the pay-offs in the game. In the absence of corruption the Monopolist earns an exogenous non-corrupt gross profit: $\Pi_{M}^{H}>0$. The Monopolist buys (compulsory) auditing services and additional consultancy services from the Auditor. Ex-ante the returns to the consultancy services are uncertain. As both agents are risk neutral they share this risk with a contract that has payment based upon expected returns. A constant proportion $\alpha \in[0,1)$ of the Monopolist's profit is allocated to purchase Auditor consultancy services. The Monopolist's gross non-corrupt profit reflects productive and market characteristics and benefits from these Auditor services. If in the first stage of the game the Monopolist opts for the Honest action, rather than Corrupt choice, then after taking into account the costs of the Auditor's consulting services, the Monopolist's net non-corrupt profit is: $\Pi_{M}\left\{H_{1}, \ldots\right\} \equiv \Pi_{M}^{H}(1-\alpha)$.

We now characterise corruption opportunities in the game. The Monopolist has an opportunity to undertake a corrupt activity yielding income $\gamma(g) \Pi_{M}^{H}$. The parameter $g \in[0, \infty)$ measures the extent of the corrupt activity whilst $\gamma(g)$ is a (production) function which determines the value of corruption income relative to the exogenous noncorrupt gross Monopoly profit. The (production) function $\gamma(g)$ is continuous and concave on $g$, reflecting diminishing returns: $\gamma(g)>0, \gamma^{\prime \prime}(g), \forall g \in(0, \infty)$. Corruption produces an additional gross profit gain (before taking into account consultancy fees and any penalties for detected corruption) to the Monopolist over the non-corrupt gross Monopoly profit: $\Pi_{M}^{C} \equiv(1+\gamma(g)) \Pi_{M}^{H}$. 
Figure 1: Extensive form representation of the corruption game

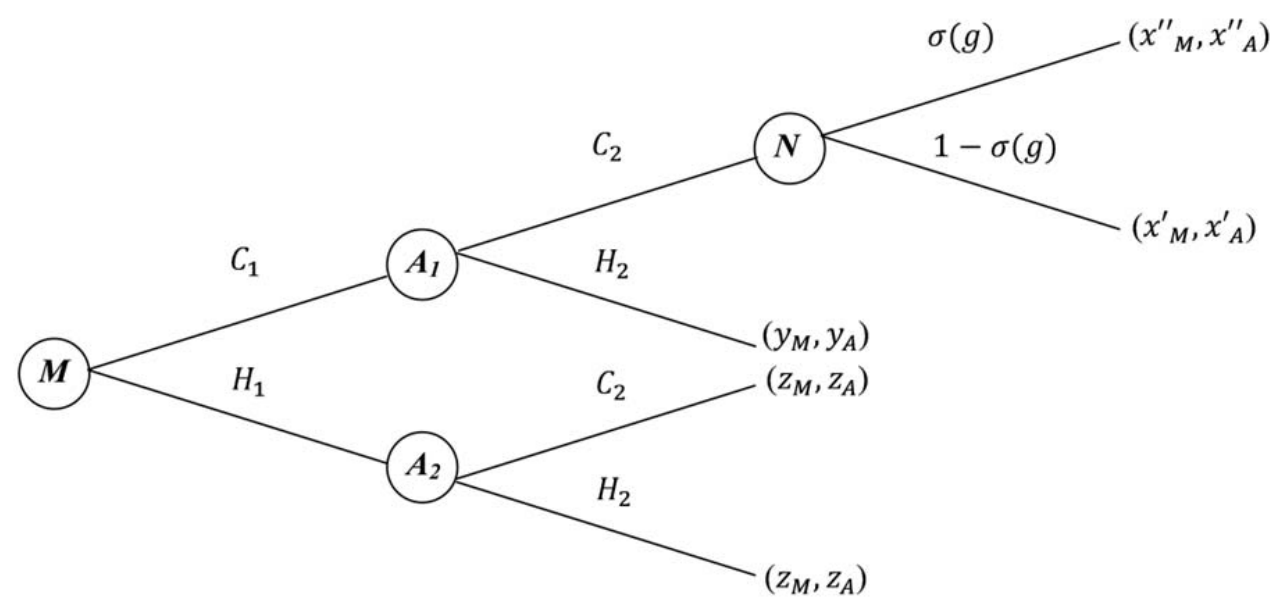

The game is illustrated in extensive form in Figure 1 . Nodes $M$ and $N$ relate to the Monopolist and Nature, respectively, and nodes $A_{1}$ and $A_{2}$ relate to the Auditor. Payoffs (which are derived in Section 3 ) are reported in parentheses.

It is important to note that in this paper the level of corruption $g$ is not a (continuous) choice variable of the Monopolist. Rather, the Monopolist faces a discrete choice between not being corrupt $\left\{H_{1}, \ldots\right\}$ and pursuing a corrupt prospect, $g^{*}$, under $\left\{C_{1}, \ldots\right\}$, of value $\gamma\left(g^{*}\right) \Pi_{M}^{H}$. This reflects the fact that in many cases a firm may have a limited set of opportunities for corrupt activities making $g$ discrete rather than continuous. The assumption also enables a simplified analysis, not least by eliminating the need to determine an optimal level of $g$. Indeed, to further simplify matters, we allow the discrete prospect to be the open ball with centre $g^{*}$ and radius $\rho$. Assuming $\rho$ to be sufficiently small means that we can avoid uninteresting mixed strategy Nash equilibria in the game which are defined only on point values of $g^{* 2}$

In the second stage of the game, the Auditor makes its choice between Corrupt and Honest having observed the action of the Monopolist in the first stage of the game. If the Monopolist has chosen to be corrupt and the Auditor opts for honesty $\left\{C_{1}, H_{2}\right\}$, then the Monopolist is penalised with a fine $F_{M}>0$ with certainty. In the case where both players choose to be corrupt the payoff to each agent is uncertain as Nature assigns a probability $\sigma(g)$ to the corrupt activity being detected. If the corruption is detected a strictly positive

\footnotetext{
${ }^{2}$ Hence, where such a special case arises we let the Monopolist move infinitesimally to the left or the right of $g^{*}$ into an interval of $g$ characterised by a pure strategy Nash equilibrium in such a way that it is at least no worse off.
} 
penalty is imposed on both Monopolist $\left(F_{M}>0\right)$ and Auditor $\left(F_{A}>0\right)$. Under the assumptions of the game, the players' payoffs following Nature's actions under $\left\{C_{1}, C_{2}\right\}$ can be represented by an 'expected' payoff with probability weights $\sigma(g)$ and $1-\sigma(g)$. Note, that by restricting the action set of the two players to $\{C, H\}$ we rule out any action on the part of the Auditor that would involve it misleading the regulatory authorities by indicating that the Monopolist has been corrupt when it has not been corrupt as well as any retaliation by the Monopolist to $\left\{\mathrm{C}_{1}, \mathrm{H}_{2}\right\} .{ }^{3}$ The implication of this is that we can restrict analysis to a two-stage, rather than three-stage, game.

In the main, costs are not specified explicitly within the model (they play an unspecified role in $\Pi^{H}$ and $\omega(g)$, defined later), however, the following assumption introduces a cost differential for the Auditor under corruption relative to honest behaviour. We assume that the Auditor incurs a $\operatorname{cost} c_{A}$ associated with supplying services to the Monopolist. These costs are higher under $\left\{C_{1}, C_{2}\right\}$ than under $\left\{\ldots, H_{2}\right\}: c_{A}^{C}>c_{A}^{H}$. The cost differential is defined $\Delta c \equiv c_{A}^{C}-c_{A}^{H}>0$ and is assumed to be constant (not a function of the level of corruption) and $\Delta c<\alpha F_{M}{ }^{4}$ We argue that the positive differential is a sensible assumption given the higher transaction costs involved with hiding corrupt practices. $^{5}$

\subsection{Payoff specification and equilibria}

In this subsection we specify an explicit payoff structure for the corruption game set out above. First, the payoffs corresponding to $z$ in Figure 1 are:

$$
\begin{aligned}
& z_{M} \equiv \Pi_{M}\left\{H_{1}, H_{2}\right\} \equiv \Pi_{M}\left\{H_{1}, C_{2}\right\} \equiv(1-\alpha) \Pi_{M}^{H} \\
& z_{A} \equiv \Pi_{A}\left\{H_{1}, H_{2}\right\} \equiv \Pi_{A}\left\{H_{1}, C_{2}\right\} \equiv \alpha \Pi_{M}^{H}-c_{A}^{H}
\end{aligned}
$$

Given the Monopolist faces a certain punishment cost of $F_{M}$ if the Auditor does not support its corruption, the payoffs corresponding to $y$ in Figure 1 are:

$$
\begin{aligned}
& y_{M} \equiv \Pi_{M}\left\{C_{1}, H_{2}\right\} \equiv(1-\alpha)\left[(1+\gamma(g)) \Pi_{M}^{H}-F_{M}\right] \\
& y_{A} \equiv \Pi_{A}\left\{C_{1}, H_{2}\right\} \equiv \alpha\left[(1+\gamma(g)) \Pi_{M}^{H}-F_{M}\right]-c_{A}^{H}
\end{aligned}
$$

\footnotetext{
${ }^{3}$ This restriction of the model seems reasonable because if the Monopolist sacks the Auditor for failing to support a corrupt strategy this would involve public disclosure of the corruption.

${ }^{4}$ In a broader model than that set out here this positive cost differential could be reinforced by the expected costs due to reputational damage to the Auditor under the corrupt option in terms, for instance, of lost future earnings.

${ }^{5}$ As we see later (after Lemma 2), $\Delta c<\alpha F_{M}$ ensures that the set of values of $g$ for which the Auditor would support corruption is non-empty.
} 
If the Auditor colludes in the corruption the probability of corruption being detected is $\sigma(g)$. If the Auditor is found to be corrupt there is a punishment cost of $F_{A}$. In the case that corruption is not detected, the payoff to the Monopolist and Auditor, corresponding to $x^{\prime}$ in Figure 1, are respectively:

$$
\begin{aligned}
& x_{M}^{\prime} \equiv(1-\alpha)\left[(1+\gamma(g)) \Pi_{M}^{H}\right] \\
& x_{A}^{\prime} \equiv \alpha\left[(1+\gamma(g)) \Pi_{M}^{H}\right]-c_{A}^{C}
\end{aligned}
$$

whilst the payoffs, if they are caught (corresponding to $x^{\prime \prime}$ in Figure 1), are respectively:

$$
\begin{aligned}
& x_{M}^{\prime \prime} \equiv(1-\alpha)\left[(1+\gamma(g)) \Pi_{M}^{H}-F_{M}\right] \\
& x_{A}^{\prime \prime} \equiv \alpha\left[(1+\gamma(g)) \Pi_{M}^{H}-F_{M}\right]-c_{A}^{C}-F_{A}
\end{aligned}
$$

Hence, the expected payoffs to the Monopolist and Auditor under $\left\{C_{1}, C_{2}\right\}$ are:

$$
\begin{aligned}
& x_{M} \equiv E\left(\Pi_{M}\left\{C_{1}, C_{2}\right\}\right) \equiv(1-\alpha)\left[(1+\gamma(g)) \Pi_{M}^{H}-\sigma(g) F_{M}\right] \\
& x_{A} \equiv E\left(\Pi_{A}\left\{C_{1}, C_{2}\right\}\right) \equiv \alpha\left[(1+\gamma(g)) \Pi_{M}^{H}-\sigma(g) F_{M}\right]-c_{A}^{C}-\sigma(g) F_{A}
\end{aligned}
$$

The system of equations defined by Eqs. 1, 2 and 5 can be used to derive the conditions under which each of the three scenarios in the game is a Unique Perfect Nash Equilibrium (UPNE). We begin by identifying the conditions under which each scenario is a UPNE. Given the earlier assumption about the discrete nature of the corrupt opportunity $g^{*}$ available to the Monopolist, we rule out any mixed strategy Nash equilibria (which occur in this game only at specific individual values of $g$ ).

UPNE 1. This equilibrium involves both the Monopolist and Auditor opting to be corrupt: $\left\{C_{1}, C_{2}\right\}$. From Figure 1 this corruption equilibrium requires $x_{A}>y_{A}$ and $x_{M}>z_{M}$, hence, respectively, from Eqs. 1a, 2a, 5a and 5b:

$$
\begin{aligned}
& \frac{\sigma(g) F_{A}+\Delta c}{1-\sigma(g)}<\alpha F_{M} \\
& \frac{\Pi_{M}^{H}}{F_{M}} \gamma(g)>\sigma(g)
\end{aligned}
$$

Hence, from Eq. 6a, the Auditor's share $(\alpha)$ of the penalty $\left(F_{M}\right)$, that the monopolist doesn't incur under undetected corruption, weighted by the probability of this event $(1-\sigma(g))$ is greater than the additional cost to the Auditor of it covering up the corruption $(\Delta c)$ plus the penalty it pays for being caught colluding in the corruption $\left(F_{A}\right)$ weighted by the probability of 
this event $(\sigma(g))$. The inequality in Eq. $6 \mathrm{~b}$ simply requires that the gain in profit for the Monopolist under undetected corruption is greater than the penalty to the Monopolist weighted by the probability of detection.

UPNE 2. $\left\{C_{1}, H_{2}\right\}$ This equilibrium involves attempted Monopoly corruption controlled by the Auditor. In terms of Figure 1 it requires $x_{A}<y_{A}$ and $y_{M}>z_{M}$, hence, respectively, from Eqs. 1a, 2a, 2b and 5b:

$$
\begin{aligned}
& \frac{\sigma(g) F_{A}+\Delta c}{1-\sigma(g)}>\alpha F_{M} \\
& \frac{\Pi_{M}^{H}}{F_{M}} \gamma(g)>1
\end{aligned}
$$

Hence, for the Auditor, the expected value of the Auditor's fine plus the costs of it covering up the corruption are greater than the expected gains from covering up the corruption in terms of the consultancy income for the Auditor (i.e. if the corruption is not detected then the Monopolist will not be fined $F_{M}$ and the Auditor will gain consultancy income of $\alpha F_{M}$ from this). For the Monopolist, the value of the gain in profit from the corrupt activity exceeds the value of the fine.

UPNE 3. $\left\{H_{1}, H_{2}\right\} \equiv\left\{H_{1}, C_{2}\right\}$ This 'honesty' equilibrium arises under two different sets of circumstances, if: (i) $x_{A}>y_{A}, z_{M}>x_{M}$, requiring, respectively Eq. $6 \mathrm{a}$ and:

$$
\frac{\Pi_{M}^{H}}{F_{M}} \gamma(g)<\sigma(g)
$$

and(ii) $x_{A}<y_{A}, z_{M}>y_{M}$, requiring, respectivelyEq. $7 \mathrm{a}$, and:

$$
\frac{\Pi_{M}^{H}}{F_{M}} \gamma(g)<1
$$

Remark 1. For completeness, note, there are no pure strategy pure Nash equilibria (PNE) under $x_{A}>y_{A}$ where either (i) $x_{M}>z_{M}>y_{M}$, or (ii) $y_{M}>z_{M}>x_{M}$.

Hence, in the first case, the Auditor's expected gain from hiding the corruption is positive but the Monopolist's expected gain from corruption is negative. In the second case, the fine for the Monopolist, which will happen with certainty given the Auditor will be honest, is less than the gain in profit due to the corrupt activity. 


\subsection{Corruption detection and corruption technology profiles}

The main results of our paper will depend upon the size of the corruption prospect available to the Monopolist, $g^{*}$, and the properties of $\gamma(g)$ and $\sigma(g)$ which collectively determine the size of the "expected" reward to corrupt activity for the players. In order to formalise the analysis, we will make some assumptions about the properties of $\gamma(g)$ and $\sigma(g)$. We begin with the relationship $\sigma(g)$, which we term as the corruption detection profile. The functional form of this term determines how the probability of detected collusion varies with the size of the corrupt prospect.

We introduce the first of a number of critical values of $g$ that will be helpful in specifying the properties of $\sigma(g)$.

Definition 1. $\hat{g} \equiv \inf \{g: \sigma(g)=1\}$

We now introduce two specifications of the corruption detection profile, $\sigma_{j}(g) j \in\{1,2\}$. In both cases $\sigma(0)=0$, however $\sigma_{1}(g)$ is strictly convex and monotonically increasing until $g=\hat{g}$, where it reaches unity and remains at unity for all $g>\hat{g}$. On the other hand, $\sigma_{2}(g)$ is strictly concave and monotonically increasing everywhere with limit $T<1$. The two profiles are illustrated in Figure 2, where the $y$-axis is the probability of detection.

Thus, $\sigma(\mathrm{g})$ is positive monotonic for $\sigma(\mathrm{g})<1$, which would appear to be reasonable as higher levels of corruption, g, are likely to be more conspicuous and hence more likely to be detected.

Figure 2: Corruption Detection Profiles

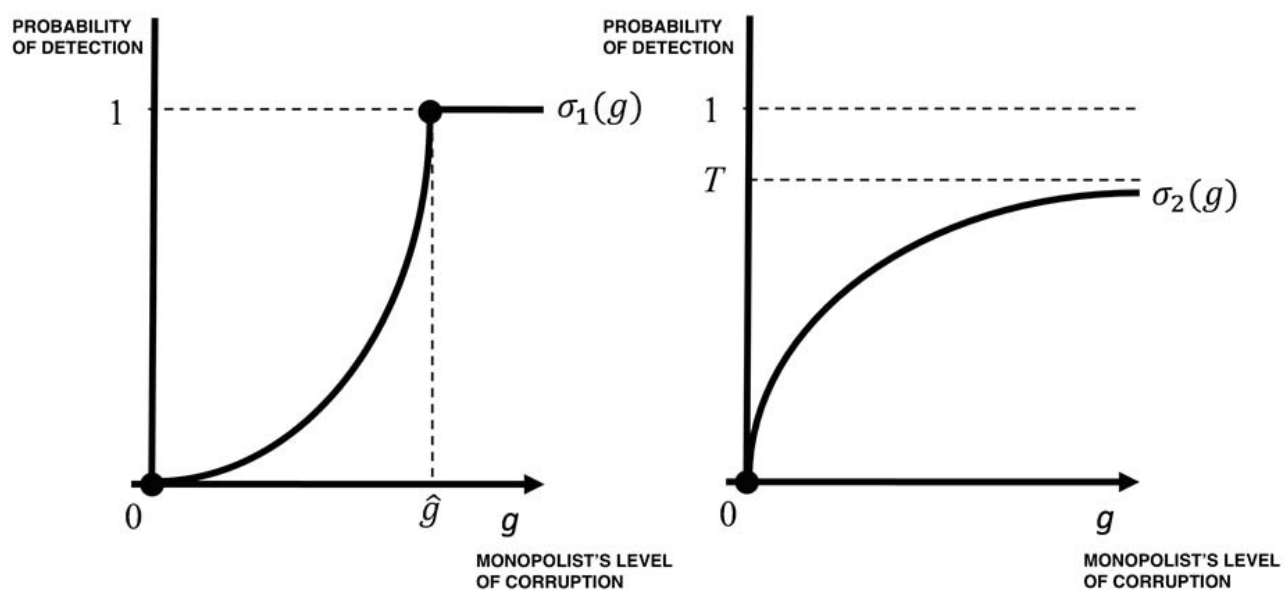


In the case of $\sigma_{1}(g)$, sufficiently high levels of corrupt activity will eventually result in the corruption being detected with certainty. However under $\sigma_{2}(g)$ higher levels of corrupt activity will raise the probability of detection but never to the extent that corruption will be detected with certainty.

We now turn to the specific question of the circumstances under which the Auditor will choose corruption over honesty for which the term $\varphi(\sigma)$ is instrumental. The key properties of this term are set out in the following Lemma.

Lemma 1. ${ }^{6} \varphi(\sigma) \equiv \frac{\sigma}{1-\sigma} F_{A}+\frac{\Delta c}{1-\sigma}$ is: (i) positive monotonic in $\sigma$, (ii) convex in $\sigma$, (iii) $\lim _{\sigma \rightarrow 1^{-}} \varphi(\sigma)=\infty$, and (iv) (weakly) increasing in $\left(F_{A}\right) \Delta c$.

As we will see, this result is of some importance in delivering Lemma 2. The following critical value, where it exists, is useful in identifying the optimal action of the Auditor in this game.

Definition 2. Let $g^{* *} \equiv\left\{g: \varphi(\sigma(g))=\alpha F_{M}\right\}$.

We are now able to state the following Lemma.

Lemma 2. The Auditor will support Monopoly corruption (be honest) iff $\boldsymbol{\sigma}\left(\boldsymbol{g}^{*}\right)<[>] \boldsymbol{\sigma}\left(\boldsymbol{g}^{* *}\right)$ and hence $\boldsymbol{g}^{*}<[>] \boldsymbol{g}^{* *}$.

Hence, $g^{* *}$ defines the level of corruption which produces a detection probability under which the Auditor is indifferent between $\left\{C_{1}, H_{2}\right\}$ and $\left\{C_{1}, C_{2}\right\}$ and that for $g^{*}<[>] g^{* *}$ the Auditor would support [not support] a corrupt Monopolist. Illustrating with reference to Figure 3, the Auditor will choose to be corrupt if the corruption prospect $g^{*}$ available to the Monopolist is smaller than $g^{* *}$ and so in the case depicted, the Auditor will choose to be corrupt.

The role of Lemma 1 is now clear. Given, by assumption, $\Delta c<\alpha F_{M}$, at $\sigma=0$ we have $\varphi(0)<\alpha F_{M}$ and hence the Auditor is honest. Since $\varphi(\sigma)$ is monotonically increasing, there is an open interval $\left(0, \sigma\left(g^{* *}\right)\right)$ for which $\varphi(\sigma)<\alpha F_{M}$, and hence the Auditor supports corruption, despite a strictly positive probability of detection. Further, that $\varphi(\sigma)$ is convex and asymptotic to $\sigma=1$, and $\alpha F_{M}$ is finite, ensures that there is a probability of detection at which the Auditor is honest: $\varphi(\sigma)$ crosses the line $\alpha F_{M}$. Of course, the critical probability here is lower as $\Delta c$ is closer to $\alpha F_{M}$, and/or the function $\varphi(\sigma)$ is more convex.

In order to help understand the factors affecting the choice of the Monopolist we now introduce the corruption technology profile, $\omega(g) \equiv \frac{\Pi_{M}^{\mathrm{H}}}{F_{M}} \gamma(g)$. This profile relates the level of $g$ to the reward available to the Monopolist from being corrupt relative to the fine if caught.

\footnotetext{
${ }^{6}$ Where proofs are provided they are reported in the Appendix.
} 
Figure 3: Auditor's Decision

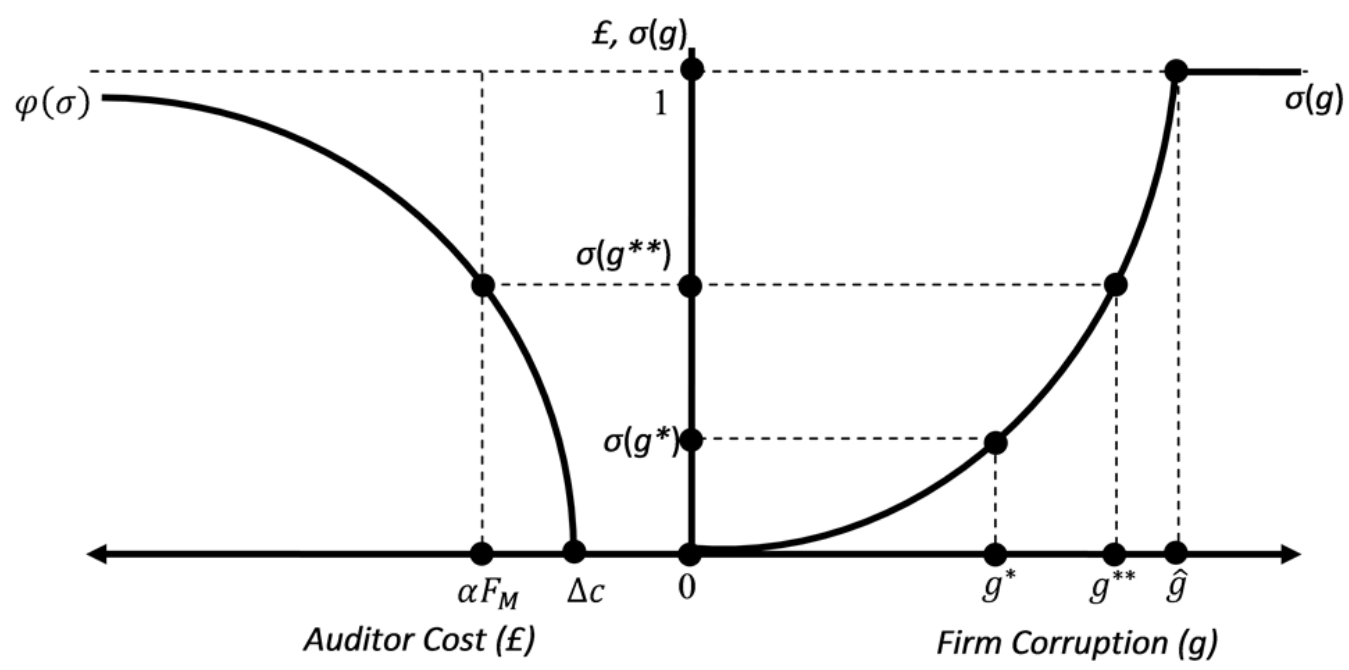

We focus attention on this term, rather than just the underlying $\gamma(g)$ term, because of the importance of the relative Monopolist reward to corruption in determining the outcome of the game - note $\omega(g)$ is the L.H.S. of Eqs. $6 \mathrm{~b}$ and $7 \mathrm{~b}$, and so on. Some properties of $\omega(g)$ are set out below.

Lemma 3. $\omega(\mathrm{g})$ is (i) continuous, and (ii) strictly concave.

Hence $\omega(g)$ is concave reflecting diminishing returns to corruption as implied by the properties of $\gamma(g)$. The following defines a further critical value of $g$ which is important for characterising the properties of $\omega(g)$

Definition 3. Let $\tilde{g} \equiv \inf \{\mathrm{g}: \omega(\mathrm{g})=1\}$.

We can now outline the relationships between the level of Monopolist corruption and the return to corruption, specifying two corruption technology profiles, $\omega_{i}(g)(i \in\{a, b\})$, illustrated in Figure 4. In addition to the properties of $\omega(g)$ in Lemma 3 (continuity and strict concavity), we have that: $\omega_{a}(g)$ and $\omega_{b}(g)$ exhibit 'weak' diminishing returns (so that although strictly concave, they are monotonically increasing in $g$ and don't have downward sloping sections) tending to limits of $V>1$ and $S<1$, respectively. Hence, the additional income from the corrupt activity is always greater than the cost (not including any 
DIETRICH, MCHARDY, SHARMA Firm Corruption in the Presence of an Auditor

Figure 4: Two Corruption Technology Profiles $\boldsymbol{\omega}_{\boldsymbol{i}}(\boldsymbol{g})(\boldsymbol{i} \in\{\boldsymbol{a}, \boldsymbol{b}\})$
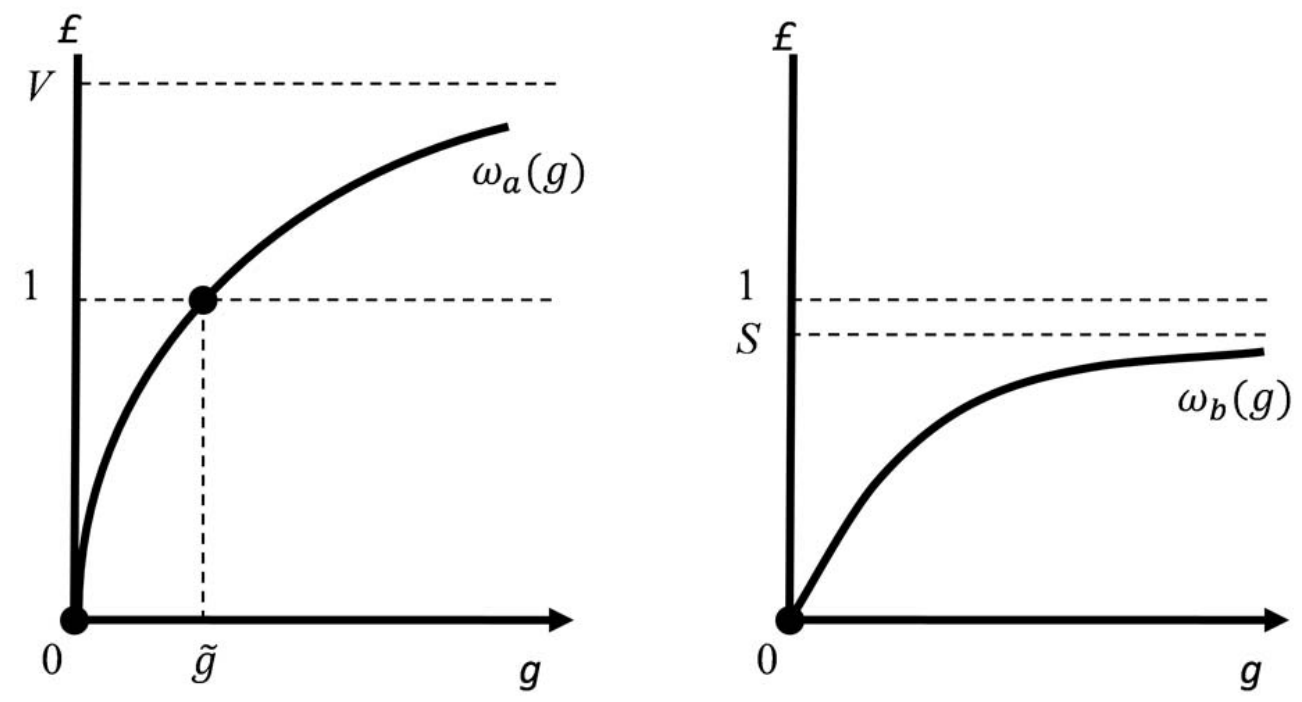

detection penalties) of undertaking the corrupt activity. We select these functional forms not with an intention of explaining every possible technology but rather to show how different types of technology will support different equilibria and have different implications for policy making whilst keeping the analysis as straightforward as possible. Combinations of the two corruption technology profiles, $\omega \_\mathrm{i}(\mathrm{g})(\mathrm{i} \in\{\mathrm{a}, \mathrm{b}\})$, and the two corruption detection profiles, $\sigma \_j(g)(j \in\{1,2\})$, give rise to four cases which we label Case ji.

To make the analysis manageable and for simplicity, we stipulate that the two functions $\omega$ and $\sigma$ only cross at most once to the left of $\hat{g}$ i.e. where $\sigma$ is strictly upward sloping. These Case classifications will help identify conditions under which certain outcomes of policy actions are, and are not, effective. The following critical values of $g$ are useful in characterising the relationship between $\omega(g)$ and $\sigma(g)$.

\section{Definition 4. Let $\quad$ (i) $\bar{g} \equiv \inf \left\{\mathrm{g}: \omega(\mathrm{g})=\sigma(\mathrm{g}), \mathrm{g} \in \mathbb{R}_{++}\right\}$;}

(ii) $\overline{\bar{g}} \equiv \sup \{\mathrm{g}: \omega(\mathrm{g})=\sigma(\mathrm{g})\}$

A non-exhaustive set of examples of the four cases are illustrated in Figure 5 where critical values of $g$ are indicated selectively. The solid black lines represent $\sigma(g)$ whilst the grey lines represent $\omega(g)$. As will become clear later, the outcome of the game will depend on the relative position of certain critical values of $g$ and $g^{*}$.

The different grey lines in Figure 5 serve to offer an illustration of what can happen to the relative position of critical values of $g$ as either $\sigma(g)$ stretches up and/or to the right or $\omega(\mathrm{g})$ 
shifts upwards and/or to the left. Again, these are not exhaustive but help in understanding aspects of the policy analysis in Section 3. In particular, policy outcomes will depend on such things as whether $\omega(0)$ is steeper or flatter than $\sigma(0)$ and the limit of $\sigma \_2(\mathrm{~g})(\mathrm{T})$ lies above or below the limit of $\omega \_b(g)(S)$.

Figure 5: Examples of the Relationship between Corruption Technology profile $\boldsymbol{\omega}_{\boldsymbol{i}}(\boldsymbol{g})$ $(\boldsymbol{i} \in\{\boldsymbol{a}, \boldsymbol{b}\})$ and the Corruption Detection Profile $\boldsymbol{\sigma}_{j}(\boldsymbol{g})(\boldsymbol{j} \in\{\boldsymbol{a}, \boldsymbol{b}\})$ in the Cases $\boldsymbol{j i}$
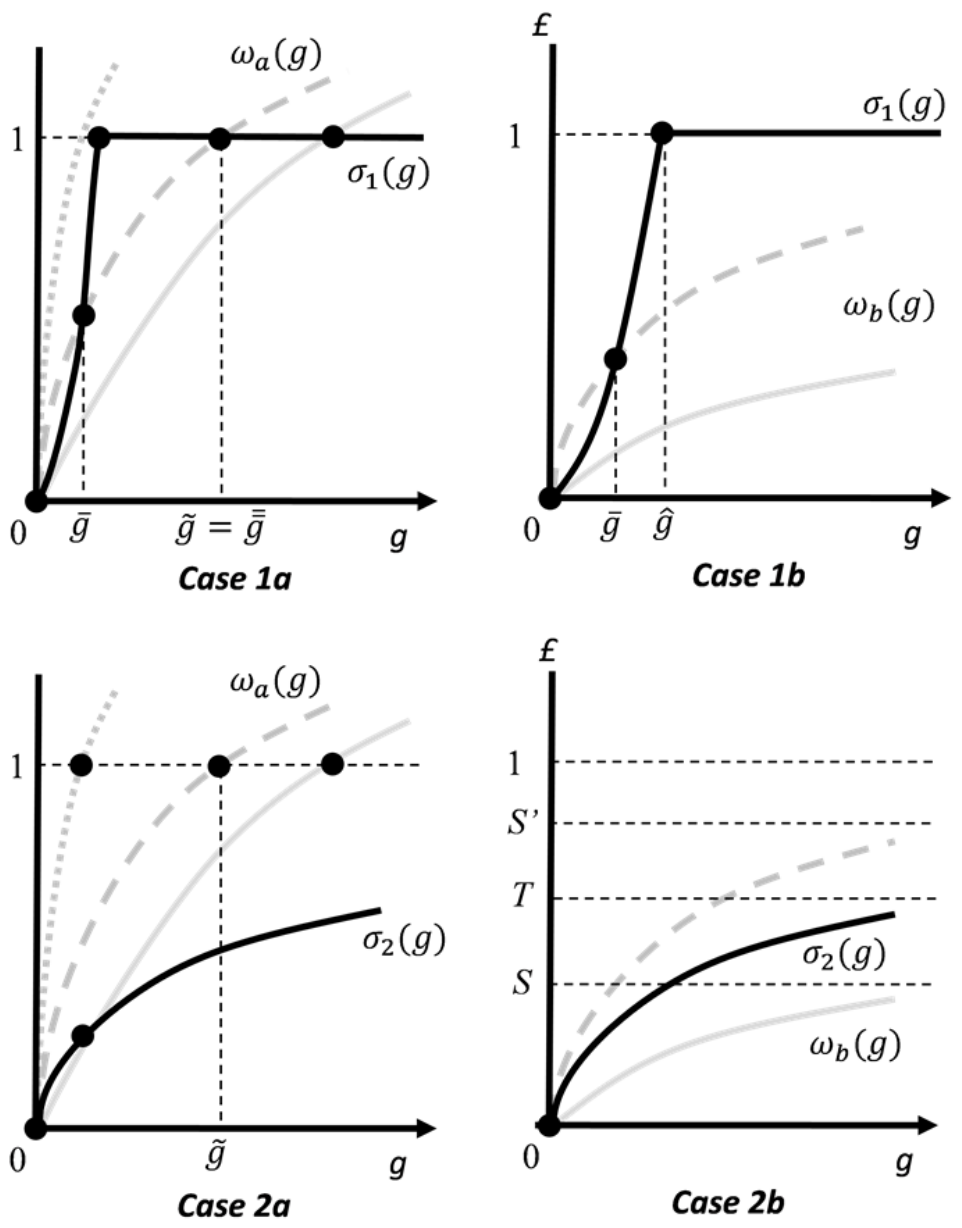

Key: Black - Corruption detection profile $\sigma(g)$; Grey - Corruption technology profile $\omega(g)$ (i) Grey Solid - $\sigma^{\prime}(0)>\omega^{\prime}(0)$ (ii) Grey Dash $-\sigma^{\prime}(0)<\omega^{\prime}(0)$ and $\hat{g}<\tilde{g}$; (iii) Grey Dots - $\sigma^{\prime}(0)<\omega^{\prime}(0)$ and $\hat{g}>\tilde{g}$ 
DIETRICH, MCHARDY, SHARMA Firm Corruption in the Presence of an Auditor

\subsection{Some properties of the model}

Remembering that $g^{*}$ is not a (continuous) choice variable, there is a clear way of ranking the three UPNE from a public policy point of view at a given level of $g^{*}$. UPNE3 is the most desirable outcome as this involves the guarantee of no corrupt activity. UPNE1 is clearly the least desirable outcome as corrupt activities may be going on undetected. UPNE2 is an improvement upon UPNE1 inasmuch as corruption, although it is not prevented, is detected through the functioning of the Auditor. Similarly, cases where UPNE2 supports unconstrained corruption may involve very high levels of abuse which, though not avoided, are detected, whilst unconstrained corruption under UPNE1 may be very high and go undetected.

Definition 5. Labeling UPNEk ( $k \in\{1,2,3\})$, corruption equilibria are monotonically 'worsening' ['improving'] in $g^{*}$ if increasing $g^{*}$ leads to smaller [larger] $k$ for $\forall g^{*} \in(0, \infty)$.

Under Definition 5, Figure 6 illustrates examples of monotonically improving, worsening, and non-monotonic orderings of UPNEk with increases in the size of the corruption prospect, $g^{*}$.

Figure 6(i) illustrates the case of a non monotonic ordering of UPNEk with increases in $g^{*}$. For $g^{*}<g^{* *}$ we have UPNE1 with both Auditor and Monopolist choosing corruption. However, raising $g^{*}$ above $g^{* *}$ but below $\bar{g}$ yields $U P N E 2$, with further increases yielding, respectively $U P N E 3$, for $g^{*}$ between $\bar{g}$ and $\tilde{g}$, and UPNE2, for $g^{*}$ above $\tilde{g}$ Figure 6(ii) also begins with UPNE1, then UPNE2 but, for $g^{*}$ above $\bar{g}$, yields UPNE3, and so is monotonically improving with $g^{*}$. Conversely, Figure 6(iii) illustrates a situation with UPNE2, for $g^{*}$ below $\bar{g}$, and $U P N E 3$, for $g^{*}$ above $\bar{g}$.

Lemma 4. For a given Case $(i \in\{a, b\}, j \in\{1,2\})$, the associated UPNEk are not always monotonically worsening or improving in $g^{*}$.

Hence, across the possible combinations of corruption technology and detection pro- files, there is no uniform pattern of UPNEk worsening or improving as the Monopolist is faced with higher levels of the corruption prospect, $g^{*}$. It is useful to identify situations where the $\sigma(g)$ and $\omega(g)$ profiles yield UPNEk $k \in\{1,2,3\}$ that are effectively unconstrained and those that are constrained. We explain what is meant in each case with the help of the following Definition.

Definition 6. (i) $U P N E \mathrm{k}$ is said to be unconstrained if $g^{*}$ is $U P N E \mathrm{k}$ for $\forall g \in[d, \infty)$ where $d$ is finite and $d \in \mathbb{R}_{++}$; (ii) UPNEk is said to be constrained if $g^{*}$ is UPNEk for $\forall g \in[d, e]$ where $d$ and $e$ are finite, $d, e \in \mathbb{R}_{++} ;$and $d \leq e$. 
Figure 6: Examples of monotonically improving, worsening and non monotonic orderings of $U P N E \mathrm{k}$ with increases in $\boldsymbol{g}^{*}$

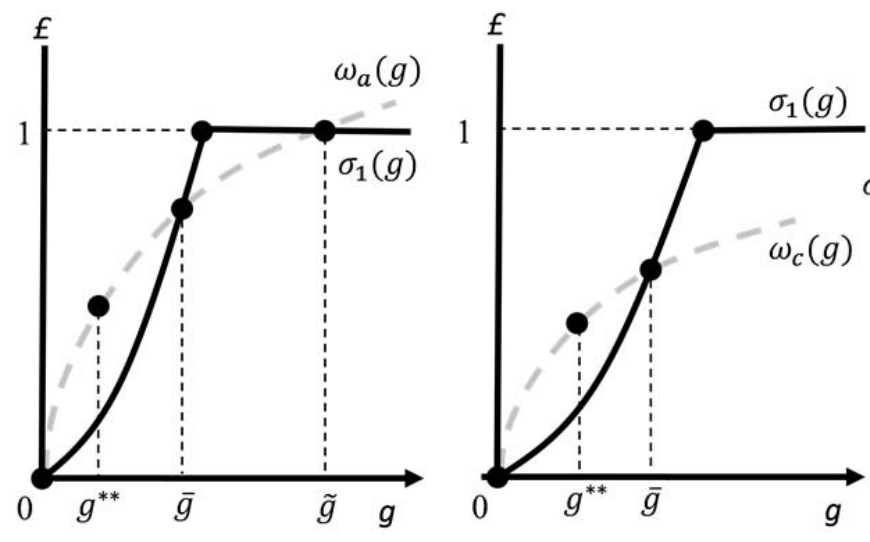

(i) Non Monotonic (ii) Monotonically Improving

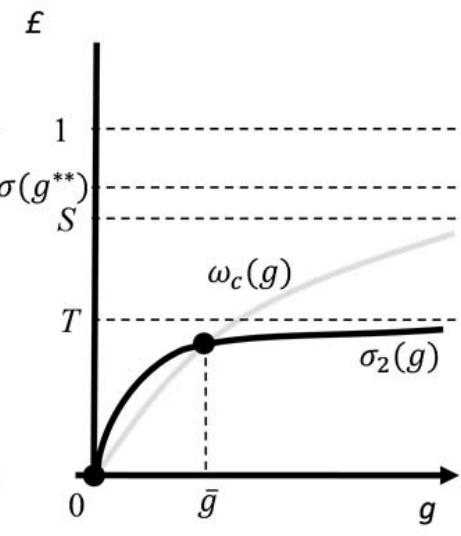

(iii) Monotonically Worsening

The following Lemma is immediately apparent.

Hence, scenario $k$ which is $U P N E$ at some finite $g^{*}$, is an unconstrained $U P N E$ for all higher levels of $g$. Otherwise, it is a constrained UPNE. The following Lemma illustrates some circumstances under which our model supports unconstrained UPNE or otherwise.

Lemma 5. (i) In Case $1 i i \in\{a, b\}$, UPNE1 is never unconstrained; (ii) In Case $1 a$, UPNE2 is always unconstrained; (iii) In Case $j a j \in\{1,2\}$, UPNE3 is never unconstrained; (iv) In Case 2a, UPNE1 [UPNE2] is unconstrained if $T<\sigma\left(g^{* *}\right)[T>$ $\sigma\left(g^{* *}\right)$ ]; (v) In Case 2a, UPNE1 [UPNE2] is unconstrained if $T<\sigma\left(g^{* *}\right)$ and $S>T$ $\left[T>\sigma\left(g^{* *}\right)\right.$ and $\left.\mathrm{S}>\mathrm{T}\right]$.

In this Section we have identified circumstances under which corruption might be an equilibrium and indeed when such an equilibrium might be unconstrained inasmuch as it remains an equilibrium regardless of how large the corrupt prospect is. In the following Section we begin to ask whether the equilibrium for a particular prospect, $g^{*}$, can be influenced by the Monopolist or regulatory authority.

\section{Policy analysis}

In this Section we consider how the parameters of the model may be manipulated so as to change the outcome of the game for a given prospect, $g^{*}$. We analyse in turn the possible impact the Monopolist can have on the equilibrium of the game and then consider the policy options 
available to the regulator to reduce the likelihood of corruption being an equilibrium using fines and investing in corruption detection. We also briefly consider the possibility of some action by the regulator to reduce the size of a given corrupt prospect $g^{*}$, which given $\omega(g)$ is a positive monotonic relationship, implies a reduction in the gains to the Monopolist through the corrupt option.

\subsection{Monopoly influence}

We begin by asking whether the Monopolist can influence the outcome of the game. Given we are assuming that the Monopolist cannot determine the level of corruption, the only other candidate for an instrument that the Monopolist might exploit is $\alpha$, the share of profit devoted to Auditor services. ${ }^{7,8}$

Proposition 1. If $\omega\left(g^{*}\right)>\sigma\left(g^{*}\right)$ and $\sigma\left(g^{*}\right)$ is greater than, but sufficiently close to, $\sigma\left(g^{* *}\right)$ then the monopolist can increase $\alpha$ strategically to move from UPNE2 to UPNE1.

Definition 7. If it exists, let $\underline{\Delta \alpha}>0$ be the value of $\Delta \alpha$ which satisfies both $\sigma\left(g^{* *}, \alpha+\right.$ $\Delta \alpha)<\sigma\left(g^{*}\right)$ and $\omega\left(g^{*}, \alpha+\Delta \alpha\right)>\sigma\left(g^{*}\right)$, where $\omega\left(g^{*}, \alpha\right)>\sigma\left(g^{*}\right)$ and $\sigma\left(g^{*}\right)>$ $\sigma\left(g^{* *}, \alpha\right)$.

Hence, if $\underline{\Delta \alpha}$ exists then it is possible for the Monopolist to move the game from UPNE2 to UPNE1. It follows that the Monopolist may be able to exploit consultancy fees to 'bribe' the Auditor to be complicit in its corruption. However, although UPNE1 may be 'better' than UPNE2 for the Monopolist, inasmuch as it moves the Monopolist from a situation of incurring the fine $F_{M}$ with certainty, to incurring it with some positive probability $\sigma\left(g^{*}\right)<1,{ }^{9}$ the above Proposition only establishes that there are circumstances under which it might bring about such manipulation of the Auditor. We now address the question regarding the conditions under which such manipulation would be in the interests of the Monopolist.

\footnotetext{
${ }^{7}$ It is conceivable that the Monopolist might be able to influence the profile $\gamma(g)$. However, in order to analyse this we would require a formal specification of the costs involved and this lies beyond the scope of the current work.

${ }^{8}$ In what follows we allow $\alpha$ to change with no impact on the underlying gross-non corrupt Monopoly profit, $\Pi^{H}$. So effectively an increase in $\alpha$ here is a simple transfer which can be interpreted as a bribe. In practice a higher $\alpha$ involves buying more Auditor services and this would impact on the underlying profit of the Monopolist. Given we have not specified how the underlying profit story unfolds, in order to keep the analysis as simple as possible, letting $\alpha$ affect underlying profitability is beyond the scope of the paper, although it is readily seen that such an extension need not meaningfully change the nature of the results.

${ }^{9}$ By definition, under UPNE1, $\sigma\left(g^{*}\right)<\sigma\left(g^{* *}\right)<1$.
} 
Proposition 2. The Monopolist optimally selects to increase $\alpha$ by an amount $\Delta \alpha$ in order to bring about a move from UPNE2 to UPNE1 if:

$$
\Delta \alpha<\frac{(1-\alpha)(1-\sigma(g)) F_{M}}{\left\{(1+\gamma(g)) \Pi_{M}^{H}-\sigma(g) F_{M}\right\}}
$$

Definition 8. Let

$$
\overline{\Delta \alpha} \equiv \frac{(1-\alpha)(1-\sigma(g)) F_{M}}{\left\{(1+\gamma(g)) \Pi_{M}^{H}-\sigma(g) F_{M}\right\}}
$$

Lemma 6. Although it is possible for the denominator of Eq. 9 to be non-positive, for $\left\{C_{1}, C_{2}\right\}$ to be a UPNE requires that $(1+\gamma(g)) \Pi_{M}^{H}-\sigma(g) F_{M}>0$, hence where the strategy of using $\alpha$ to move from UPNE2 to UPNE1 is feasible, then the denominator of Eq. 9 is positive.

Remark 2. If $\underline{\Delta \alpha} \in(0, \overline{\Delta \alpha})$ then the Monopolist can and will optimally raise $\alpha$ to move the game from UPNE2 to UPNE1.

Proposition 3. The range of values of $\Delta \alpha$ which are consistent with the Monopolist optimally choosing to stimulate a move from UPNE2 to $U P N E 1, \Delta \alpha \in(0, \overline{\Delta \alpha})$, is (i) decreasing in $\alpha, \Pi_{M}^{H}$ and $\gamma(g)$, (ii) increasing in $F_{M}$ and (iii) may be increasing or decreasing in $\sigma(g)$.

It follows from Proposition 3(ii) that subject to UPNE1 and UPNE2 both being feasible following an increase in $F_{M}$, such an increase in the fine to the Monopolist will increase the range of values of $\Delta \alpha$ which would make a move from UPNE2 to UPNE1 attractive to the Monopolist. As we will see later, such an increase in $F_{M}$ will also have a perverse effect on the Auditor which reinforces the likelihood of a move from UPNE2 to UPNE1 being feasible and optimal.

\subsection{Regulation through fines}

We now ask whether the regulatory body can influence the outcome of the game. The two obvious factors that the regulator can manipulate are the fines (to the Auditor $\left(F_{A}\right)$ and the Monopolist $\left(F_{M}\right)$ upon detection of corruption) and the probability of detection (by investing in the detection framework). We begin by examining the impact upon the game of raising the penalty to the Monopolist, $F_{M}$. 
Proposition 4. Increasing the Monopolist's fine under detected corruption, $F_{M}$, can (i) eliminate all corruption with a sufficiently high fine, and (ii) perversely, incentivise UPNE1 over UPNE2.

Essentially, Proposition 4(i) refers to a case where $\omega(g)$ is lowered sufficiently that the corruption profile ends up resembling Case 1b illustrated in Figure 5 where $\omega_{b}^{\prime}(0)<\sigma_{1}{ }^{\prime}(0)$ ( $\omega_{b}$ is the bold grey line). Proposition 4(ii) illustrates one example of the possible nonmonotonicity of UPNEk in $F_{M}$. This result presents a warning to regulators that increasing the fine to the Monopolist upon detection of corruption may have perverse effects if the fine is not set sufficiently high. It does, however, also lead to the following Corollary.

Corollary 1. The regulatory authority can bring about a move from UPNE1 to UPNE2, causing the Auditor to be honest instead of supporting Monopoly corruption, by decreasing the monopoly penalty, $F_{M}$.

We now examine the implications for the game of the regulator increasing the fine to the Auditor with corruption detected under UPNE1.

Proposition 5. Increasing the fine to the Auditor, $F_{A}$, on detection of UPNE1 corruption (i) unambiguously reduces the range of $g^{*}$ over which the Auditor will choose to be complicit in corrupt activities, promoting UPNE2 over UPNE1, (ii) but cannot eliminate UPNE2.

Hence, sufficiently large fines for the Monopolist (Auditor) can (can not) eliminate corruption altogether, though marginal increases in the Monopoly fine can result in the Auditor optimally supporting the Monopolist's corruption where before it was honest.

\subsection{Regulation reducing the corrupt prospect $g^{*}$}

In this section we briefly consider the potential for the regulator to reduce corruption by reducing the size of the discrete corrupt prospect $g^{*}$ available to the Monopolist. It is possible to imagine that regulations which, for instance, reduce the avenues for tax avoidance, might present such an example. Proposition 6 follows immediately from Lemma 4.

Proposition 6. (i) If the regulatory authority does not know the nature of the corruption technology and detection profiles then it cannot predict whether action to reduce the size of the Monopolist's corrupt prospect $g^{*}$ will improve or worsen the resulting equilibrium as understood in Definition 5. (ii) Similarly, if the regulatory authority knows the exact Case $j i$ but doesn't know how sensitive the size of the prospect $g^{*}$ is to a given tightening of its policy 
then it may not know whether tightening its policy will improve or worsen the resulting equilibrium, for instanceleap-frogging the preferred equilibriuminto a worse equilibrium.

In other words, even though we have set out to keep the specifications of $\sigma(g)$ and $\omega(g)$ as simple as possible, our model gives rise to non-uniform and possibly non-monotonic sequences of equilibria for increasing $g^{*}$ making the outcomes of policy interventions to reduce the size of $g^{*}$ unpredictable and risky.

\subsection{Regulation through corruption detection}

Finally, we consider the possibility that the regulator could invest in improving the corruption detection framework, raising $\sigma(g)$.

Assumption 1. We assume, for simplicity, that investments in improving the corruption detection framework cause the profile $\sigma(g)$ to rise $\forall g \in(0, \hat{g})[\forall g \in(0, \infty)]$ in the case of $\sigma_{1}\left[\sigma_{2}\right]$ so that the properties of the profile under the definition of $\sigma_{1}\left[\sigma_{2}\right]$ are preserved.

Under Assumption 1 it follows that if $T>\sigma^{* *}$ so that $g^{* *}$ does not exist, then a sufficiently large investment in improving detection will eventually yield $T<\sigma^{* *}$ for which there will exist an associated $g^{* *}$. However, investment in improving detection cannot convert a $\sigma_{2}(g)$ detection profile into a $\sigma_{1}(g)$ profile: if the initial profile is $\sigma_{2}(g)$ (where the probability of detection is always strictly below unity), then under Assumption 1 corruption detection investment can'tgenerate an outcome where detection of corruption is a certainty.

We begin by considering the impact of investing in improved detection upon the Auditor.

Proposition 7. Investment in corruption detection (i) under $\sigma_{1}$, and also $\sigma_{2}$ for $T>S$, unambiguously reduces the range of $g^{*}$ for which the Auditor will choose to be complicit in corrupt activities, promoting UPNE2 over UPNE1, (ii) under $\sigma_{2}$ in the case of $T \leq S$ will reduce the range of $g^{*}$ for which the Auditor will choose to be complicit only if the resulting shift in $\sigma_{2}$ is sufficiently large.

It follows that investments in improving corruption detection may have no effect upon the Auditor unless they are sufficiently large, hence local adjustments in the detection may not have any impact upon the range of $\sigma_{2}$ supporting UPNE2. We now turn our attention to the impact of investments in corruption detection on the Monopolist.

Proposition 8. Investments in improving corruption detection, however large, are completely ineffective at eliminating Monopoly corruption or even reducing the range of $g^{*}$ for which the Monopolist is corrupt where corruption arises under technology $a$ in the region $\omega_{a}>1$. 
Corollary 2. Investments in improving corruption detection are completely ineffective at addressing unconstrained UPNE2 under technology $\omega_{\mathrm{a}}$.

Thus, whilst improving detection may deter the Auditor from being complicit in corrupt activities, on its own, this policy cannot eliminate all corruption, including possible unconstrained corruption. Also, we know from Proposition 7 that such investments will eventually deter the Auditor from supporting corrupt activities, hence the most that could be achieved with this policy of improving corruption detection is to eliminate UPNE1. UPNE2 cannot be eliminated in this case, however much investment is undertaken.

Finally, we show that investments in corruption detection may or may not have any impact upon the range of $g^{*}$ over which the Monopolist chooses to be corrupt. We use the idea of arbitrarily small changes in corruption detection investment in order to emphasise that after the investment the local properties of the model are unchanged and we have not made a shift from one Case to another.

Proposition 9. Arbitrarily small investments in improving corruption detection which preserve the original Case $j i$ (i) are completely ineffective in dealing with Monopolist corruption in Case $1 i$ with $\omega^{\prime}(0)<\sigma^{\prime}(0)$; (ii) always reduce the range of $g^{*}$ for which the Monopolist chooses to be corrupt under Case $1 i$ with $\omega_{i}{ }^{\prime}(0)>\sigma_{1}{ }^{\prime}(0)$ and $\hat{g}<\tilde{g}$.

This reinforces the earlier point that if the policy measure taken by the regulatory body is not sufficiently large, it may be completely ineffective (not even having a marginal effect) in dealing with corruption.

\section{Conclusions}

Our paper assesses a highly relevant yet relatively neglected aspect of corruption and collusive behaviour in relation to corporate firms, as opposed to government agencies, which is the norm in this literature. The key driver to the relationship between the firm and the auditor is that increasing firm profitability from corruption indirectly increases the demand for consultancy services that the auditor provides in addition to auditing services. We demonstrate that a variety of equilibria are possible in the game, depending on particular parameterisations: corruption by both the firm and the auditor; firm corruption that is controlled by an honest auditor; and, honesty by both actors in the model.

The multiplicity of possible equilibria in the model is interesting in its own right but is particularly useful in terms of the analysis of possible policy interventions that are considered in the final substantive section. In general terms some of the policy conclusions confirm what might be considered intuitively obvious anti-corruption policy. But some of the conclusions are less intuitively obvious and reflect firm-auditor interaction. Amongst other things, we show 
that corruption is indeed an equilibrium of the game under some scenarios and also that, in general, it is not possible to say anything about whether a corrupt or honest equilibrium is likely to occur for higher or lower levels of corruption activity on offer to the Monopolist: under some scenarios the honest (corrupt) equilibrium prevails where the corrupt prospect is small (large) and vice versa. In particular, we show that the Monopolist might be able to profitably manipulate the consultancy fee it pays to the Auditor to bring about a corrupt equilibrium in which the Auditor is complicit. We also show that sufficiently high fines on the Monopolist can eliminate corruption but that generally raising the fine incurred by the Monopolist can have perverse effects, too. Fining the Auditor, on the other hand, cannot eliminate all corruption. Finally, we show that investments in corruption detection (raising the probability that corrupt activity is detected and penalised) may be effective at deterring Auditor complicity in corrupt activities but may be completely ineffective at addressing Monopoly corruption. First, the monopolist can, in principle, 'bribe' the auditor by increasing consultancy payments. The result here is that the equilibrium of the game can, in principle, be shifted from 'firm corruption that is controlled by an honest auditor' to 'corruption by both the firm and the auditor'. Secondly, even without the firm strategically buying consultancy services, increasing penalties on corrupt firms can be shown to undermine auditor honesty; a conclusion that follows from the interactions in the model. It follows that the efficiency of the auditing system may be improved by reducing penalties on corrupt firms.

Consequently it appears that imposing penalties on corrupt firms may be an inefficient policy option and should be used in combination with, or replaced by, other policy options. There is the obvious option of punishing auditors. It has been shown here that this unambiguously promotes auditor honesty and does not have the perverse effects that can be identified when corrupt monopolists are punished. But auditor punishment does not remove firm corruption. Instead it results in a more effective auditing system. It follows that possible anti-social effects of corruption not considered here (for instance on consumers or other economic actors) still exist. A similar conclusion follows from investment in the detection of firm corruption. This can be shown to not eliminate corruption instead it promotes auditor honesty.

It is appropriate to mention various policy options that appear intuitively plausible but go beyond the confines of the model presented here. First, there is the possibility of making penalties endogenous and hence increasing with corrupt gains. This might eventually eliminate large scale corruption, but depending on the function used to define the penalties, need not eliminate the perverse impacts of firm penalties in general. Another issue that can be highlighted involves the non-monotonicity of the equilibria. Without a detailed picture of the relevant corruption detection and technology profiles it is not possible to say whether policies aimed at 'getting tough' on corruption are necessary, productive or indeed, 
DIETRICH, MCHARDY, SHARMA Firm Corruption in the Presence of an Auditor

counterproductive. This is interesting and counterfactual to the prevailing popular narrative aiming for (further) penal regulatory responses.

\section{Appendix A: Proofs}

\section{Proof of Lemma 1.}

By assumption (i) $F_{A}$ and $\Delta c$ are strictly positive, hence (ii) $\varphi^{\prime}(\sigma)=\frac{F_{A}}{1-\sigma}+\frac{\sigma F_{A}+\Delta c}{(1-\sigma)^{2}}>0$ and (ii) $\varphi^{\prime \prime}(\sigma)=2 \frac{F_{A}}{(1-\sigma)^{2}}+2 \frac{\sigma F_{A}+\Delta c}{(1-\sigma)^{3}}>0$. (iii) Since $F_{A}$ and $\Delta c$ are exogenous and finite, $\lim _{\sigma \rightarrow 1^{-}} \frac{1}{1-\sigma}=0$, and so $\lim _{\sigma \rightarrow 1^{-}} \varphi(\sigma)=\infty$. (iv) Given $\sigma \in[0,1]$, then $\frac{\partial \varphi(\sigma)}{\partial F_{A}} \geq 0$ and $\frac{\partial \varphi(\sigma)}{\partial \Delta c}>0$.

\section{Proof of Lemma 2.}

First, note that $\varphi(\sigma(g))$ is the L.H.S. of Eqs. 6a and 7a and so by Definition 2 $\varphi\left(\sigma\left(g^{* *}\right)\right)=\alpha F_{M}$ and the Agent is indifferent between being corrupt and honest. Given, from Lemma $1 \varphi(\sigma)$ is positive monotonic and strictly convex such that it is asymptotic to $\sigma=1, \varphi(\sigma)=\alpha F_{M}$ must occur for $\sigma \in(0,1)$, as $\alpha F_{M}$ is finite. Further, since $\sigma_{j}(g)$ is positive monotonic for $\sigma<1$, if $g^{*}<[>] g^{* *}$ then $\sigma^{*}<[>] \sigma^{* *}$ and $\varphi(\sigma)<[>] \alpha F_{M}$, hence the Auditor will support corruption [be honest].

\section{Proof of Lemma 3.}

Given $\Pi_{M}^{H}$ and $F_{M}$ are strictly positive and exogenous, the proof follows from the properties of $\gamma(g)$.

\section{Proof of Lemma 5.}

(i) It is sufficient to note that under Case $1 i, \sigma_{1}(g)$ reaches unity at $\hat{g}$ which guarantees the Auditor will not support corruption at that point or for higher $g$. (ii) Since $\lim _{g \rightarrow \infty} \omega_{a}(g)=V>1$, under Case $1 a$, the reward to corruption for the Monopolist is always sufficient to compensate for the fine which results with certainty under Auditor honesty. (iii) Since $\lim _{g \rightarrow \infty} \omega_{a}(g)=V>1$ ensuring the Monopolist will choose corruption regardless of the Auditor's decision. (iv) This follows from (iii) with UPNE1 (UPNE2) being unconstrained if at the limit, $\sigma_{2}$ does not (does) reach the level $\sigma\left(g^{* *}\right)$ required to make the Auditor honest. (v) This is an extension of (iv), though with $\omega_{b}$, corruption requires $\omega_{b}>\sigma_{2}$ as $g \rightarrow \infty$, and hence $S>T$. 


\section{Proof of Proposition 1.}

Let $\omega\left(g^{*}\right)$ at some initial level of $\alpha$ be $\omega\left(g^{*}, \alpha\right)$ where $\omega\left(g^{*}, \alpha\right)>\sigma\left(g^{*}\right)$. Accordingly, let $\sigma\left(g^{*}\right)>\sigma\left(g^{* *}, \alpha\right)$ so that we have UPNE2 at $\alpha$. Increasing $\alpha$ shifts $\alpha F_{M}$ (in Figure 2) to the left raising $\sigma\left(g^{* *}\right)$. However, given $\omega\left(g^{*}, \alpha\right)>\sigma\left(g^{*}\right)$, it follows there exists some $\Delta \alpha>0$ such that $\omega\left(g^{*}, \alpha+\Delta \alpha\right)>\sigma\left(g^{*}\right)$. If $\sigma\left(g^{* *}, \alpha\right)$ is sufficiently close to $\sigma\left(g^{*}\right)$, then $\sigma\left(g^{* *}, \alpha+\right.$ $\Delta \alpha)<\sigma\left(g^{*}\right)$, hence yielding UPNE1.

\section{Proof of Proposition 2.}

It is required to show that the (risk-neutral) Monopolist's expected profit under UPNE1 with $\alpha+\Delta \alpha$ is greater than the Monopolist's profit under UPNE2 with $\alpha$. Replacing $\alpha$ in Eq. 5a with $\alpha+\Delta \alpha$ and comparing with Eq. 2a we have Eq. 9.

\section{Proof of Lemma 6.}

From Eq. 6b UPNE1 requires that $\omega(g)>\sigma(g)$, hence $\frac{\Pi_{M}^{H}}{F_{M}} \gamma(g)>\sigma(g)$. Multiplying by $F_{M}$ and rearranging, we have $\gamma(g) \Pi_{M}^{H}-\sigma(g) F_{M}>0$, hence $1+\gamma(g) \Pi_{M}^{H}-\sigma(g) F_{M}>0$.

\section{Proof of Proposition 3.}

(i) This follows directly from the observation that $-\alpha$ appears only in the numerator of Eq. 9 whilst $\gamma(g)$ and $\Pi_{M}^{H}$ both appear only in the denominator of Eq. 9 with positive coefficients, hence the respective partial derivatives of $\overline{\Delta \alpha}$ in each Case are negative. (ii) This follows given, after some manipulation:

$$
\frac{\partial \overline{\Delta \alpha}}{\partial F_{M}}=\frac{(1-\alpha)(1-\sigma(g))\left[(1+\gamma(g)) \Pi_{M}^{H}\right]}{\{.\}^{2}}>0
$$

where $\{$.$\} is the denominator in Eq. 9, and given the assumptions of the model, the$ numerator of the derivative is positive. (iii) Given:

$$
\frac{\partial \overline{\Delta \alpha}}{\partial \sigma(g)}=\frac{(1-\sigma(g))-\left[(1+\gamma(g)) \Pi_{M}^{H}-\sigma(g) F_{M}\right]}{\{.\}^{2}}
$$

the first term in the numerator $(1-\sigma(g))$ is non-negative by the assumptions of the model and [.] is also positive from Lemma 6. 
DIETRICH, MCHARDY, SHARMA Firm Corruption in the Presence of an Auditor

\section{Proof of Proposition 4.}

(i) For $\left\{C_{1}, C_{2}\right\}$ to be UPNE requires, from Eq. 6a, that $\omega(g) \equiv \frac{\gamma(g) \Pi_{M}^{H}}{F_{M}}>\sigma(g)$ and for $\left\{C_{1}, H_{2}\right\}$ to be $U P N E$ requires, from Eq. $7 \mathrm{~b}$, that $\omega(g) \equiv \frac{\gamma(g) \Pi_{M}^{H}}{F_{M}}>1$. Hence, to rule out $U P N E 1$ and UPNE2, respectively requires that $\sigma(g) F_{M}>\Pi_{M}^{H}$ and $F_{M}>\Pi_{M}^{H}$. (ii) Let $\omega(g)$ at some initial level of $F_{M}$ be $\omega\left(g, F_{M}\right)$, where $\omega\left(g, F_{M}\right)>\sigma(g)$. Accordingly, let $\sigma\left(g^{*}\right)>$ $\sigma\left(g^{* *}, F_{M}\right)$ so that we have UPNE2. Increasing $F_{M}$ shifts $\alpha F_{M}$ in Figure 2 to the left raising $\sigma\left(g^{* *}\right)$. However, given $\sigma\left(g^{*}, F_{M}\right)>\sigma\left(g^{*}\right)$, it follows there exists some $\Delta F_{M}>0$ such that $\omega\left(g^{*}, F_{M}+\Delta F_{M}\right)>\sigma\left(g^{*}\right)$. If $\sigma\left(g^{* *}, F_{M}\right)$ is sufficiently close to $\sigma\left(g^{*}\right)$, then $\sigma\left(g^{* *}, F_{M}+\right.$ $\left.\Delta F_{M}\right)<\sigma\left(g^{*}\right)$, hence yielding $U P N E 1$.

\section{Proof of Proposition 5.}

(i) This follows straightforwardly from Definition 2. Increasing $F_{A}$ raises $\varphi(\sigma)$ for $\forall \sigma \in(0,1)$. Since, from Eq. 6a, UPNE1 requires that $\varphi(\sigma)<\alpha F_{M}$, increasing $\varphi(\sigma)$ reduces $\sigma\left(g^{* *}\right)$, the supremum of the set of $\sigma(g)$ for which the Auditor would support Monopoly corruption. (ii) This follows straightforwardly from the observation that $F_{A}$ does not feature in the Monopolist's condition for UPNE2.

\section{Proof of Proposition 7.}

(i) For this proof it is convenient to exploit the strict monotonicity of $\sigma(g)\left[\sigma^{\prime}(g)>0\right]$ for $\sigma \in[0,1)][\sigma \in(0, \infty)]$ under $\sigma_{1}\left[\sigma_{2}\right]$. This allows us to invert the function giving $g(\sigma)$ for $\sigma_{1} \in[0,1)$ and $\sigma_{2} \in[0, T)$. Under $\sigma_{1}, \sigma\left(g^{* *}\right) \in(0,1)$ exists and under $\sigma_{2}$ with $T>S$, $\sigma\left(g^{* *}\right) \in(0, T)$ exists. Hence, inverting the function we can say in each case $g\left(\sigma^{* *}\right)$ exists. Given $\sigma^{* *}$ is determined by the interaction of $\varphi(\sigma)$ and $\alpha F_{M}$, neither of which are affected by raising the $\sigma(g)$ profile, then $\sigma^{* *}$ is constant. However, an upward shift in $\sigma_{1}(g)$ for $\sigma \in(0,1)$ implies $g\left(\sigma^{* *}\right)$, and hence $g^{* *}$, falls. A similar argument holds for an upward shift in $\sigma_{2}$ for $\sigma \in(0, T)$. Since the Auditor's complicity in corruption requires that $g^{*} \in$ $\left(0, g^{* *}\right)$ the range of values of $g^{*}$ consistent with Auditor complicity has fallen. (ii) It is sufficient to note that under $\sigma_{2}$ in the case of $T \leq S, \sigma^{* *}$ lies strictly above $\sigma_{2} \forall g \in[0, \infty)$, hence $g^{* *}$ does not exist. However, since $\sigma^{* *}$ is fixed and lies in the open interval $(0,1)$ there always exists a $\sigma>\sigma^{* *}$ in the interval $(0,1)$. Hence, a sufficiently large investment in improving detection will eventually shift $\sigma_{2}$ upwards raising $T$ above $S$ so that $g^{* *}$ exists. This reduces the interval of $g^{*}$ under which the Auditor will be complicit in corruption from $(0, \infty)$ to $\left(0, g^{* *}\right)$. Further improvements in corruption detection will then have the effect described in (i). 


\section{Proof of Proposition 8.}

This follows straight forwardly from the observation that UPNE2 requires $\omega>\sigma$ but since $\omega>1$ and $\sigma$ is constrained to lie at or below 1, any feasible increase in $\sigma$ will not be enough to reverse the inequality between $\sigma$ and $\omega$.

\section{Proof of Proposition 9.}

(i) This follows directly from the fact that under Case 1 the only corrupt equilibrium is UPNE2 where $\omega_{a}>1$, which, from Proposition 8 , we know cannot be affected by detection investments. (ii) First, if $g^{* *}>\bar{g}$ then Monopolist corruption occurs if $g^{*} \in(0, \bar{g})$. Investing in improving corruption detection will raise $\sigma_{1}(g)$ hence reducing $\bar{g}$ and with it the upper limit of $g^{*}$ consistent with Monopolist corruption. Second, if $g^{* *} \leq \bar{g}$ then Monopolist corruption occurs if $g^{*} \in\left(0, g^{* *}\right)$. Investing in improving corruption detection raises $\sigma_{1}(g)$, which by Proposition 7(i) reduces $g^{* *}$, and with it the upper limit of $g^{*}$ consistent with Monopolist corruption. 
DIETRICH, MCHARDY, SHARMA Firm Corruption in the Presence of an Auditor

\section{References}

Aglietta, M., Reberioux, A., 2005. Corporate Governance Adrift. Edward Elgar Publishing Limited, Cheltenham.

Arezki, R., B. M., 2011. Oil rents, corruption, and state stability: Evidence from panel data regressions. European Economic Review 55, 955-963.

Armantier, O., B. A., 2011. A controlled field experiment on corruption. European Economic Review 55, 1072-1082.

Carrillo, J., 2000. Graft, bribes, and the practice of corruption. Journal of Economics and Management Strategy 9, 257-286.

Coffee, J., 2005. A theory of corporate scandals: Why the USA and Europe differ. Oxford Review of Economic Policy 21, 198-211.

Çule, M., Fulton, M., 2009. Business culture and tax evasion: Why corruption and the unofficial economy can persist. Journal of Economic Behavior \& Organization 72 (3), 811-822.

Dufwenberg, M., Spagnolo, G. 2015. Legalizing bribe giving. Economic Inquiry 53 (2), 836-853.

Goel, R., 2014. PACking a punch: Political Action Committees and corruption. Applied Economics 46 (11), 1161-1169.

Innes, R., Mitra, A. 2014. Is dishonesty contagious. Economic Inquiry 51 (1), 722-734.

Ivanyna, M., Moumouras, A., Rangazas, P. 2016. The culture of corruption, tax evasion and economic growth. Economic Inquiry 54 (1), 520-542.

Jensen, M., 2006. The agency costs of overvalued equity. In: Glyn, A., Jenkinson, T. (Eds.), Capitalism Unleashed: finance, globalization and welfare. Oxford University Press, Oxford.

Laffont, J., N'Guessan, T., 1999. Competition and corruption in an agency relationship. Journal of Development Economics 60 (2), 271-295.

Lambert-Mogiliansky, A., Sonin, K., 2006. Collusive market sharing and corruption in procurement. Journal of Economics and Management Strategy 15, 883-908.

Lessmann, C., Markwardt, G., Apr 2010. One size fits all? Decentralization, corruption, and the monitoring of bureaucrats. World Development 38 (4), 631-646.

Mishra, A., 2006. Persistence of corruption: some theoretical perspectives. World Development 34 (2), 349-358.

Wadho, W. A. 2016. What determines corruption? International evidence from microdata. Economic Inquiry 46 (4), 493-510.

Pagano, M., Immordino, G., September 2007. Optimal regulation of auditing. CESifo Economic Studies 53 (3), 363-388. 
Posner, R., 2006. From the new institutional economics to organizational economics: with applications to corporate governance, government agencies, and legal institutions. Journal of Institutional Economics 6, 1-37.

Ravikumar, B., Zhang, Y., 2012. Optimal auditing and insurance in a dynamic model of tax compliance. Theoretical Economics 7 (2), 241-282.

Rose-Ackerman, S., 1999. Corruption and Government: causes, consequences and reform. Cambridge University Press, Cambridge.

Rose-Ackerman, S., 2007. International Handbook on the Economics of Corruption. Edward Elgar Publishing Limited, Cheltenham.

Samuel, A., 2009. Preemptive collusion among corruptible law enforcers. Journal of Economic Behavior \& Organization 71 (2), 441-450.

Stiglitz, J., 2003. The roaring nineties: a new history of the world's most prosperous decade. W. W. Norton \& Co, New York.

Svensson, J., 2005. Eight questions about corruption. Journal of Economic Perspectives 19, $19-42$.

Wadho, W. A. 2016. Corruption, tax evasion and the role of wage incentives with endogenous monitoring technology. Economic Inquiry 54 (1), 391-407.

Waller, C. J., Verdier, T., Gardner, R. 2002. Corruption: Top down or bottom up? Economic Inquiry $51(1), 722-734$. 